\title{
PENERAPAN ART THERAPY DENGAN PENDEKATAN KELOMPOK UNTUK MENURUNKAN KECEMASAN PADA ANAK BINAAN DI LPKA TANGERANG
}

\author{
Ikhsan Bella Persada ${ }^{1}$, dan Agustina ${ }^{2}$ \\ ${ }^{1}$ Fakultas Psikologi, Universitas Tarumanagara Jakarta \\ Email:Ikhsan.persada94@gmail.com \\ ${ }^{2}$ Fakultas Psikologi, Universitas Tarumanagara Jakarta \\ Email: agustina@fpsi.untar.ac.id
}

\begin{abstract}
ABSTRAK
Dalam sistem peradilan, remaja yang berhadapan hukum akan ditempatkan di Lembaga Khusus Pembinaan Anak (LPKA). Hidup di LPKA merupakan pengalaman kehidupan yang penuh dengan tekanan. Tekanan yang dialami karena mereka tidak lagi memiliki kebebasan akibat jauh dari orangtua, teman sebaya, dan harus menjalani pembinaan di Lapas menimbulkan perasaan negatif seperti timbulnya kecemasan. Kecemasan tersebut merupakan rasa khawatir tentang masa depan yang menimbulkan perasaan tidak jelas, tidak pasti dan kegelisahan. Hal tersebut timbul karena ketidakmampuan individu menyesuaikan diri terhadap perubahan yang terjadi. Art therapy diketahui dapat menurunkan kecemasan pada individu. Dengan ini, penelitian ini bertujuan untuk mengetahui apakah penerapan art therapy dengan pendekatan kelompok dapat menurunkan kecemasan pada Anak didik LPKA. Desain penelitian yang digunakan adalah kuasi-eksperimen. Teknik pengambilan sampel purposive sampling dilakukan dengan memberikan alat ukur State Trate Anxiety for Children-Trait (STAIC-T) yang telah dimodifikasi untuk melihat tingkat kecemasan partisipan. 5 dari 50 partisipan terpilih dan peneliti mengambil data individual menggunakan wawancara, tes grafis (Draw a Person, BAUM. \& Wartegg Test). Setelah 8 sesi intervensi, diketahui bahwa terdapat penurunan tingkat kecemasan pada partisipan dengan adanya perubahan kualitas gambar dan penurunan skor pada alat ukur STAIC-T. Hal tersebut menunjukkan bahwa art therapy dengan pendekatan kelompok ternyata efektif dalam membantu menurunkan kecemasan.
\end{abstract}

Kata Kunci: art therapy, kecemasan, Anak didik LPKA

\section{ABSTRACT}

In the justice system, adolescents who break the law will be placed in the Special Child Development Institute (LPKA). Life in LPKA is a stressful experience. Being away from their parents, peers, and being forced to undergo coaching in correctional facility creates anxiety. Anxiety is a sense of worry about the future that causes feelings of disorientation, uncertainty and uneasiness. It arises from the inability of individuals to adjust to the changes that occur. Art therapy is known to reduce anxiety in individuals. Considering this fact, this study aims to determine whether the application of art therapy with a group approach can reduce anxiety in LPKA students. The research design used was quasi-experimental. The purposive sampling technique was carried out by providing a modified State Trate Anxiety for Children-Trait (STAIC-T) measuring tool to measure participants' anxiety levels. 5 out of 50 participants were selected and researchers took individual data using interviews, graphic tests (Draw a Person, BAUM. \& Wartegg Test). After 8 intervention sessions, a decrease in the level of anxiety of participants was found, with a change in image quality and a decrease in scores of STAIC-T. This indicates that art therapy with a group approach was effective in reducing anxiety.

Keywords: art therapy, anxiety, LPKA students

\section{PENDAHULUAN}

\section{Latar belakang}

Kejahatan merupakan suatu permasalahan yang selalu ada di setiap negara, meskipun dalam negara tersebut sudah memiliki aturan hukum dan berbagai usaha yang dilakukan oleh penegak hukum dalam mengurangi tindak kejahatan masih terasa belum mampu mengurangi tindak kejahatan yang terjadi. Permasalahan tersebut juga ditemukan pada remaja yang mengalami masalah sosial yang ditunjukkan dalam bentuk perbuatan kriminal. Berdasarkan dari data KPAI 
(KPAI : Enam Tahun Terakhir, Anak Berhadapan Hukum Mencapai Angka 9.266 Kasus, 2017), sepanjang tahun 2011 hingga 2017 terdapat 9.266 kasus. Dari tahun ke tahun, jumlah paling banyak yaitu tahun 2014 dengan jumlah kasus anak berhadapan hukum mencapai 2.208 kasus.

Dalam sistem peradilan, remaja yang berhadapan dengan hukum akan ditempatkan ke Lembaga Khusus Pembinaan Anak (LPKA) sesuai dengan undang-undang yang telah ditentukan. Menurut Whitehead dan Steptoe (2007), hidup di LPKA merupakan pengalaman kehidupan yang paling penuh dengan tekanan dibandingkan dengan semua kejadian-kejadian hidup yang dialami. Remaja dihadapkan pada kenyataan bahwa mereka tinggal dalam penjara sebagai narapidana. Kenyataan ini membuat mereka tidak lagi memiliki kebebasan. akibat dari jauh dari orangtua, teman sebaya, dan lingkungannya, remaja yang menjalani pembinaan dan berada di LPKA akan mengalami pengalaman yang menyenangkan maupun kurang menyenangkan yang terjadi di LPKA dan akan menimbulkan perasaan positif atau negatif terhadap diri remaja seperti timbulnya kecemasan (Asnita, 2015).

Menurut Spielberger (1972), kecemasan adalah reaksi emosional yang tidak menyenangkan terhadap bahaya nyata atau imajiner yang disertai dengan perubahan pada sistem saraf otonom dan pengalaman subjektif sebagai "tekanan", "ketakutan", dan "kegelisahan". Selain itu, menurut (Hooley et al., 2017), kecemasan (anxiety) merupakan perasaan khawatir tentang kemungkinan bahaya pada masa depan yang menimbulkan kekhawatiran, perasaan tidak jelas, tidak pasti, dan kegelisahan akibat adanya ancaman yang dirasakan. Kecemasan pada narapidana timbul karena ketidakmampuan individu menyesuaikan diri terhadap perubahan yang terjadi. Ciri-ciri yang tampak pada narapidana yang mengalami kecemasan yaitu perasaan khawatir, takut, gelisah, bahkan kadang-kadang panik.

Dalam usaha untuk mengurangi kecemasan dapat dilakukan dengan berbagai metode, sa;ah satunya adalah art therapy. Art therapy didasarkan pada pemikiran proses kreatif pembuatan seni yaitu penyembuhan peningkatan kehidupan dan merupakan bentuk komunikasi pikiran dan perasaan nonverbal. (American Art therapy Association dalam Malchiodi, 2012). Art therapy merupakan salah satu jenis terapi yang sangat baik bagi seseorang yang mengalami gangguan emosi dan kecemasan. Ellingson (1991) memaparkan beberapa hal yang menjadi sumber kecemasan individu serta bagaimana art therapy dengan segala aktivitas di dalamnya dapat mengurangi kecemasan yang dirasakan. Salah satu sumber yang dapat menimbulkan kecemasan adalah hal-hal yang berkaitan dengan kebebasan individu. Dalam pandangan psikologis klinis, secara filosofis kebebasan dapat diartikan sebagai sebuah pengalaman yang melibatkan kesadaran individu, karena melalui kebebasan individu dapat melakukan konstruksi dunianya sendiri. Seseorang dapat secara bebas membentuk dunianya sendiri secara sadar. Ketika anak mulai berelasi satu dengan yang lain, mereka terstimulasi, mendapatkan ide, menunjukkan usaha, membantu satu sama lain, dan terkadang memutuskan secara spontan untuk bekerja sama dalam tugas gabungan (Rubin, 2010). Pada beberapa kelompok, dapat berfokus pada topik atau masalah tertentu, terutama untuk ruang lingkup yang singkat dan terbatas. Aktivitas kelompok sebaiknya mengarah kepada tema utama yang dibutuhkan (Cohn dalam Rubin, 2010).

Berdasarkan kajian-kajian literatur di atas, kecemasan pada narapidana timbul karena ketidakmampuan individu menyesuaikan diri terhadap perubahan yang terjadi. Hal tersebut juga timbul ketika narapidana akan segera keluar dari penjara atau saat mendekati masa tahanannya habis, sehingga diperlukannya intervensi psikologis untuk kelompok narapidana yang masa tahanannya akan habis. Berdasarkan penelitian yang dilakukan oleh Abbing et al. (2018) mengenai efektifitas art therapy untuk menurunkan kecemasan pada tahanan yang akan bebas. 
Hasilnya, art therapy efektif dalam menurunkan kecemasan pada narapidana yang akan bebas. Dengan demikian, terapis bertujuan untuk melihat apakah intervensi psikologis art therapy dengan pendekatan kelompok dapat menurunkan kecemasan pada anak binaan di LPKA

\section{Rumusan masalah}

Rumusan masalah dalam penelitian ini adalah "Apakah penerapan art therapy dengan pendekatan kelompok dapat mengurangi kecemasan pada anak binaan di LPKA Tangerang?"

\section{METODE PENELITIAN \\ Partisipan}

Sesi dilaksanakan bersama 5 partisipan (anak binaan) dan dilakukan secara klasikal. Kriteria partisipannya adalah anak binaan yang sedang menjalani pembinaan di LPKA tangerang. Remaja berjenis kelamin laki-laki yang berusia 16-18 tahun. Berdasarkan wawancara mendalam, masing-masing partisipan memiliki kecemasan apa yang akan mereka lalukan ketika mereka keluar dari LPKA.

\section{Persiapan dan prosedur penelitian}

Terapis melakukan seleksi awal yang dilaksanakan di Aula LPKA Tangerang. Seleksi awal terdiri dari 50 sampel awal yang kemudian dipilih berdasarkan hasil tes kecerdasan CFIT, tes Grafis (DAP, BAUM, \& WZT), dan alat ukur kecemasan State Trate Anxiety for Children-Trait (STAIC-T) yang diadaptasi dari penelitian yang dilakukan oleh Widianti (2011) di Penjara. Tes Grafis dan alat ukur STAIC-T untuk mengetahui baseline kecemasan yang dimiliki oleh anak binaan. Terapis membuat kelompok berdasarkan tingkat kecemasan yang dimiliki oleh anak binaan. Sebelum sesi intervensi dimulai, Terapis menjelaskan terlebih dahulu mengenai kecemasan pada setiap partisipan agar partisipan memahami kondisi yang dialaminya dan menjelaskan mengenai proses intervensi yang akan dilaksanakan untuk mengurangi kecemasan yang dimiliki.

\section{Desain penelitian}

Penelitian ini dilaksanakan menggunakan desain kuasi-ekperimen. Hal ini untuk melihat dampak dari intervensi yang diberikan kepada sampel tanpa adanya kelompok kontrol. Dampak dari intervensi dapat dilihat dari perbedaan skor atau tingkat kecemasan sebelum dan setelah sampel diberikan intervensi.

\section{Perlengkapan penelitian}

Perlengkapan penelitian yang dilakukan adalah lembar biodata, informed consent, Alat menggambar (kertas gambar A3, Cat Poster, kuas, palet, pensil, penghapus, gelas plastik, dan tisu).

\section{Pengukuran}

Sebelum melakukan intervensi, Terapis memberikan alat ukur yang digunakan untuk mengukur kecemasan, yaitu State Trate Anxiety for Children-Trait (STAIC-T) yang dimodifikasi oleh Widianti (2011) agar lebih sesuai dengan kondisi individu yang berada di penjara. STAIC-T terdiri dari 20 pernyataan yang seluruhnya bersifat unfavorable, dengan skor jawaban $4=$ selalu, $3=$ sering, 2=kadang-kadang, dan 1=tidak pernah. Perhitungan jumlah skor yang diperoleh kemudian dilakukan kategorisasi dengan ansietas ringan jika skornya 20-35, ansietas sedang jika skornya 35-50, ansietas berat jika skornya 51-65, dan panik jika skornya 66-80. Skor reliabilitas alat ukur STAIC-T yang telah diadaptasi oleh Widianti memiliki Cronbach Alpha sebesar 0.770 yang artinya alat ukur ini dapat digunakan. Selain itu, Terapis juga memberikan tes Grafis (DAP, 
BAUM, \& WZT) untuk membantu Terapis mengetahui kepribadian partisipan agar membantu Terapis mengetahui kecemasan yang dimiliki dan membantu Terapis dalam membimbing partisipan dalam interaksi di dalam kelompok. Selain itu, alat tes CFIT 3a untuk mengetahui tingkat inteligensi para partisipan untuk membantu Terapis mengetahui partisipan yang membutuhkan instruksi lebih detil.

\section{HASIL DAN PEMBAHASAN Gambaran partisipan}

Secara umum, kelima partisipan awalnya cukup sulit untuk berkumpul tepat waktu, namun seiring berjalannya proses intervensi, kelima partisipan dapat kooperatif dalam menjalani intervensi. Pada sesi pertama, para partisipan tampak masih belum banyak berinteraksi dengan satu sama lain dan tampak belum percaya satu sama lain sehingga ketika menceritakan pengalaman, para partisipan masih belum menceritakannya secara terbuka. Seiring berjalannya sesi, mulai sesi ke tiga, para partisipan sudah lebih terbuka dalam mengungkapkan pendapat dan ada timbal balik dalam diskusi kelompok. Diskusi kelompok dilakukan agar partisipan merasa bahwa tidak hanya diri mereka saja yang mengalami masalah yang membuatnya cemas, namun juga untuk mendapat masukan dari partisipan lain yang juga merasakan hal yang sama. Berikut ini adalah gambaran tingkat kecemasan partisipan sebelum diberikan intervensi:

Tabel 1. Gambaran Tingkat Kecemasan Partisipan

\begin{tabular}{ccc}
\hline No & Partisipan & Tingkat kecemasan (pre-test) \\
\hline 1 & ID & 58 (Berat) \\
2 & AL & 47 (Sedang) \\
3 & MF & 49 (Sedang) \\
4 & GL & 54 (Berat) \\
5 & MD & 38 (Sedang) \\
\hline
\end{tabular}

\section{Pelaksanaan Intervensi Psikologis}

Sesi intervensi dilakukan sebanyak dua kali dalam seminggu selama satu bulan. Setiap sesinya berlangsung selama 60 menit hingga 90 menit dan dilakukan dalam kelompok. Berikut ini adalah kegiatan dan tujuan dari setiap sesi intervensi yang dilaksanakan:

Tabel 2. Rancangan Intervensi

\begin{tabular}{|c|c|c|}
\hline Sesi & Kegiatan & Tujuan \\
\hline 1 & $\begin{array}{c}\text { Menjelaskan alasan pertemuan dan gambaran } \\
\text { intervensi } \\
\text { Menggambar bebas (Free drawing) (Buchlater, } \\
\text { 2009). } \\
\text { Diskusi }\end{array}$ & $\begin{array}{l}\text { Partisipan memahami aturan kelompok dan tujuan } \\
\text { intervensi art therapy. } \\
\text { Partisipan dapat secara bebas mengekspresikan diri } \\
\text { (Buchlater, 2009) } \\
\text { Partisipan belajar untuk berdiskusi dan } \\
\text { berkomunikasi satu sama lain }\end{array}$ \\
\hline 2 & $\begin{array}{c}\text { Diskusi mengenai kegiatan sesi sebelumnya dan } \\
\text { apa yang partisipan dapatkan } \\
\text { Partisipan diminta untuk menggambarkan } \\
\text { perasaan yang saat ini sedang dirasakan } \\
\text { (Buchlater, 2009) } \\
\text { Diskusi }\end{array}$ & $\begin{array}{l}\text { Partisipan mengingat kegiatan sebelumnya dan } \\
\text { mengetahui kegiatan yang dilakukan selama sesi } 1 . \\
\text { Partisipan dapat mengenal dan memahami perasaan } \\
\text { yang sedang dirasakan (Buchlater, 2009), dalam hal } \\
\text { ini kecemasan yang mereka miliki. } \\
\text { Partisipan memahami proses terapi yang dilakukan }\end{array}$ \\
\hline 3 & $\begin{array}{l}\text { Partisipan diminta melipat kertas gambar A3 } \\
\text { menjadi dua bagian. Lalu, partisipan diminta } \\
\text { menggambar pada satu sisi kertas kecemasan } \\
\text { utama yang mengganggu partisipan dan }\end{array}$ & $\begin{array}{c}\text { Partisipan dapat memahami kecemasan yang } \\
\text { dialami dan mencari cara untuk memecahkan } \\
\text { masalah yang partisipan alami. (Buchlater, 2009). }\end{array}$ \\
\hline
\end{tabular}




\begin{tabular}{|c|c|c|}
\hline & $\begin{array}{c}\text { gambarlah pada satu sisi lainnya bagaimana } \\
\text { partisipan mengatasi kecemasan tersebut } \\
\text { (Buchlater, 2009). } \\
\text { Diskusi }\end{array}$ & \\
\hline 4 & $\begin{array}{c}\text { Partisipan diminta memikirkan hal-hal apa saja } \\
\text { saat Partisipan merasa santai atau damai. Pikirkan } \\
\text { di mana Partisipan berada saat merasa santai atau } \\
\text { damai. Partisipan diminta menjelaskan } \\
\text { perasaannya saat itu. Partispan disarankan untuk } \\
\text { menggunakan warna dan bentuk yang } \\
\text { menenangkan. (Buchlaer, 2009) } \\
\text { Diskusi }\end{array}$ & $\begin{array}{l}\text { Metode untuk mencapai keadaan tenang dapat } \\
\text { dieksplorasi. Tujuannya untuk mengurangi stress } \\
\text { atau kecemasan yang dialami dan mengeksplorasi } \\
\text { kemampuan coping-nya. (Buchlater, 2009). }\end{array}$ \\
\hline 5 & $\begin{array}{c}\text { Partisipan diminta untuk menggambar hal positif } \\
\text { dalam diri sebanyak yang partisipan bisa. } \\
\text { Gambaran positif yang membuat partisipan } \\
\text { bangga dan dapat diakui orang lain. (Buchlater, } \\
\text { 2009) } \\
\text { Diskusi }\end{array}$ & $\begin{array}{l}\text { Meningkatkan kesadaran akan hal positif yang } \\
\text { diperoleh partisipan dengan kondisi saat ini. } \\
\text { Hubungan antara berpikir optimis dan kesehatan } \\
\text { mental dan fisik yang lebih baik (Buchlater, 2009). }\end{array}$ \\
\hline 6 & $\begin{array}{c}\text { Partisipan diminta untuk menggambarkan } \\
\text { kehidupan yang partisipan inginkan untuk } \\
\text { mengarahkan diri sebagai orang yang "sehat" } \\
\text { (Buchlater, 2009) } \\
\text { Diskusi }\end{array}$ & $\begin{array}{c}\text { Mengarahkan partisipan untuk fokus pada harapan } \\
\text { dan rencana di masa depan untuk menjadi diri yang } \\
\text { lebih sehat secara emosional dan psikologis } \\
\text { (Buchlater, 2009). }\end{array}$ \\
\hline 7 & $\begin{array}{l}\text { Partisipan diminta untuk menggambar pada suatu } \\
\text { kertas yang disediakan dan berpindah dari satu } \\
\text { partisipan ke Partisipan lain dalam waktu } 1 \text { menit } \\
\text { tanpa berbicara (Buchlater, 2009). } \\
\text { Diskusi }\end{array}$ & $\begin{array}{c}\text { Tujuannya untuk menyelesaikan gambar dan } \\
\text { perasaan partisipan tentang bekerja sama dengan } \\
\text { orang lain. pemecahan masalah, sharing, dan } \\
\text { sosialisasi. (Buchlater, 2009). }\end{array}$ \\
\hline 8 & $\begin{array}{c}\text { Sesi Terminasi } \\
\text { Partisipan ditunjukkan gambar-gambar yang telah } \\
\text { mereka buat dari sesi satu sampai sesi terakhir } \\
\text { Diskusi } \\
\text { Post-tes STAIC-T \& tes grafis (DAP, BAUM \& } \\
\text { WZT) }\end{array}$ & $\begin{array}{l}\text { Partisipan mengerti bahwa proses intervensi sudah } \\
\text { selesai } \\
\text { Partisipan dapat mengevaluasi proses art therapy } \\
\text { yang telah dijalani dan juga partisipan dapat } \\
\text { memberi dan mendapatkan masukan. } \\
\text { Melihat adakah perubahan kecemasan yang dialami } \\
\text { partisipan. }\end{array}$ \\
\hline
\end{tabular}

\section{Hasil intervesi}

Berdasarkan hasil dari perbandingan antara pre-test dan post-tes alat ukur STAIC-T, secara umum para partisipan mengalami penurunan kecemasan yang dilihat dari penurunan skor kecemasan. Namun, terdapat satu partisipan yang tidak menunjukkan penurunan skor. Secara keseluruhan, hal ini menunjukkan bahwa art therapy memiliki manfaat dalam menurunkan kecemasan pada anak binaan yang memiliki kecemasan apa yang akan mereka lakukan ketika keluar dari penjara. Karena berdasarkan latarbelakang penelitian ini bahwa anak-anak mengalami banyak tekanan ketika mereka masuk ke dalam penjara akibat dari perubahan lingkungan yang mereka alami. Mereka juga cenderung merasa tidak memiliki kebebasan saat masuk penjara (Whitehead \& Steptoe, 2007). Berikut ini adalah hasil perubahan tingkat kecemasan setelah intervensi:

Tabel 3. Hasil Perubahan Tingkat Kecemasan Setelah Intervensi

\begin{tabular}{cccc}
\hline Partisipan & Pre-test & Post-test & Perbedaan \\
\hline ID & 58 (Berat) & 48 (Sedang) & -10 poin \\
AL & 47 (Sedang) & 42 (Sedang) & -5 poin \\
MF & 49 (Sedang) & 42 (Sedang) & -7 poin \\
GL & 54 (Berat) & 60 (Berat) & +6 poin \\
MD & 38 (Sedang) & 30 (Ringan) & -8 poin \\
\hline
\end{tabular}


Selain dari skor pre-test dan post-test STAIC-T, penurunan kecemasan juga dapat terlihat dari hasil tes grafis dengan berkurangnya arsiran pada gambar, posisi gambar menunjukkan perubahan dan kualitas gambar menjadi lebih baik.

Berdasarkan hasil penelitian yang dilakukan, art therapy terbukti dapat mengurangi kecemasan, sama seperti yang ditemukan oleh Abbing (2018), bahwa art therapy efektif menurunkan kecemasan pada anak binaan. Meskipun begitu, hasil dari penelitian ini tidak dapat diuji secara statistik karena jumlah partisipan yang terlalu kecil, namun secara spesifik terhadap kasus yang diteliti, art therapy dapat mengurangi kecemasan pada keempat partisipan dengan penurunan poin yang variatif. Pada salah satu partisipan berinisial GL, menunjukkan adanya peningkatan skor kecemasan dan juga hasil tes grafis tidak menunjukkan adanya perubahan, hal tersebut dikarenakan berbagai faktor, beberapa faktor yang tampak adalah GL kurang aktif dalam diskusi dan selalu mengikuti jawaban yang diberikan partisipan lain sehingga ia tidak mendapatkan insight dalam setiap sesi yang dijalani. Selain itu, GL seringkali datang paling akhir dari setiap sesi yang dijalani.

\section{KESIMPULAN DAN SARAN Kesimpulan}

Berdasarkan dari hasil penelitian yang dilakukan, Intervensi kelompok dengan menggunakan pendekatan art therapy menunjukkan adanya penurunan kecemasan pada keempat subyek. Penurunan kecemasan dapat terlihat dari skor alat ukur STAIC-T dan juga hasil tes grafis (DAP, BAUM \& WZT). Hal tersebut dikarenakan art therapy membuat partisipan dapat lebih memahami kecemasan yang mereka alami dan bagaimana hal tersebut mempengaruhi mereka, sehingga art therapy dapat membantu partisipan yang sebelumnya sulit untuk mengekspresikan pemikiran dan perasaan dalam kata-kata menjadi dapat tersalurkan melalui seni atau gambar. Selain itu, art therapy dapat membantu individu untuk mencari jalan keluar dari masalah yang ia alami dan membantu individu menjadi lebih sejahtera. Individu juga tidak merasa sendiri karena setiap sesi dilakukan dengan diskusi bersama partisipan lain yang mengalami kondisi yang sama. Masing-masing partisipan dapat memperoleh penilaian positif tentang perkembangan diri partisipan.

\section{Saran}

Saran untuk penelitian selanjutnya adalah mempertimbangkan tingkat kecerdasan pada partisipan agar berada dalam tingkat kecerdasan yang sama, serta menambah sesi terapi agar partisipan memperoleh kesempatan yang lebih banyak untuk melalui proses intervensi, sehingga hasil yang diperoleh lebih signifikan.

\section{Ucapan terima kasih (Acknowledgement)}

Peneliti mengucapkan terima kasih kepada 5 partisipan dan pihak LPKA Tangerang yang sudah bekerjasama dengan peneliti, sehingga diharapkan penelitian ini dapat memberikan manfaat dan juga dapat menambah referensi dalam ilmu pengetahuan.

\section{REFERENSI}

Abbing, A, et al. (2018). The effectiveness of art therapy for anxiety in adults: A systematic review of randomised and non-randomised controlled trials. PloS one, (vol. 13 ). Di Unduh dari: https://doi.org/10.1371/journal.pone.0208716

Asnita, L., Arneliwati, \& Jumaini. (2015). Hubungan tingkat stress dengan harga diri remaja di lembaga pemasyarakatan. Jurnal ilmu keperawatan Universitas Riau. 
Buchalter, S. I. (2009). Art therapy techniques and tpplications. London, UK: Jessica Kingsley Publisher.

Ellingson, M. (1991). A philosophy for clinical art therapy. In Landgarten, H. B., Lubbers, D (Ed). Adult art psychotherapy: Issues and applications (pp. 3-20). New York, NY: Brunner/Mazel.

Hooley, J. M., Butcher, J. N., Nock, M. K., \& Mineka, S. (2017). Abnormal psychology (17th Ed.). Boston, MA: Pearson Answers.

KPAI : Enam Tahun Terakhir, Anak Berhadapan Hukum Mencapai Angka 9.266 Kasus. (2017). Di unduh dari: www.kpai.go.id/berita/kpai-enam-tahun-terakhir-anak-berhadapan-hukummencapai-angka-9-266-kasus

Malchiodi, C. A. (2012). Handbook of art therapy. New York, NY: The Guilford Press.

Rubin, J. A. (2010). Introduction to art therapy: Sources \& resources. New York, NY: Routledge

Spielberger, C. D. (1972). Current trends in theory and research on anxiety. In C. D. Spielberger (Ed.), Anxiety: Current trends in theory and research (pp. 3-9). New York and London: Academic Press

Tilton, S. R. (2008). Review of the State-Trait Anxiety Inventory (STAI). NewsNotes, 48 (2): 1-3 Whitehead, D. L., \& Steptoe, A. (2007). Prison. Elsevier. (vol. 3). 241-246. Di Unduh dari: 10.1016/B978-012373947-6.00310-X

Widianti, E. (2011). Pengaruh terapi logo dan terapi suportif kelompok terhadap ansietas remaja di rumah tahanan dan lembaga pemasyarakatan wilayah provinsi jawa barat. Tesis. Depok, Jawa Barat: Universitas Indonesia. 